\title{
Why people go for antenatal care
}

\author{
Sukfitrianty Syahrir ${ }^{1}$, Ariantika ${ }^{2}$, Abdul Majid HR. Lagu ${ }^{3}$ \\ 1,2 Bagian Gizi Universitas Islam Negeri Alauddin \\ ${ }^{3}$ Bagian Kesehatan Lingkungan Universitas Islam Negeri Alauddin
}

\begin{abstract}
One indicator of the success of development in the health sector is decreased maternal and child mortality. Efforts are being made to reduce maternal mortality rates such as the Making Pregnancy Safer (MPS) program which is a component of the Safe Motherhood initiative. One pillar is the Antenatal Care (ANC) service. This study aims to find out about the factors that influence Antenatal Care (ANC) visits. The variables studied were knowledge, distance of the house, socio-economic status, husband / family support and support of health workforces. This research was a quantitative study using a descriptive analytic approach with a cross sectional method with a population of all third trimester pregnant women who come to check their pregnancy as many as 84 pregnant women obtained in the working area of the Penrang Public Health Center in Pinrang, by using purposive sampling, a sample size of 69 respondents was obtained. The results showed that the level of knowledge, socioeconomic status, husband / family support, and support of health workforces influences antenatal care visits, while the distance of the house did not show a significant effect. We recommend to this health center to improve the provision of information about antenatal services to pregnant women and their families.
\end{abstract}

Keyword: health workforce; antenatal care; knowledge; home distance

\begin{abstract}
ABSTRAK
Salah satu indikator keberhasilan pembangunan dalam sektor kesehatan adalah menurunnya angka kematian ibu dan anak. Upaya yang dilakukan untuk menekan angka kematian ibu seperti program Making Pregnancy Safer (MPS) yang merupakan komponen dari prakarsa Safe Motherhood. Salah satu pilarnya adalah pelayanan Antenatal Care (ANC). Penelitian ini bertujuan untuk mengetahui tentang faktor yang mempengaruhi kunjungan Antenatal Care (ANC). Variabel yang diteliti adalah pengetahuan, jarak rumah, status sosial ekonomi, dukungan suami/keluarga dan dukungan petugas kesehatan. Penelitian ini adalah penelitian kuantitatif menggunakan pendekatan deskriptif analitik dengan metode cross sectional dengan populasi semua ibu hamil trimester III yang datang memeriksakan kehamilannya sebanyak $84 \mathrm{ibu}$ hamil yang diperoleh di wilayah kerja puskesmas Penrang kabupaten pinrang, dengan menggunakan purposive sampling maka diperoleh besar sampel sebanyak 69 responden. Hasil penelitian menunjukkan bahwa tingkat pengetahuan, status sosial ekonomi, dukungan suami/ keluarga, dan dukungan petugas kesehatan berpengaruh terhadap kunjungan antenatal care, sedangkan jarak rumah tidak menunjukkan pengaruh yang signifikan. Kami merekomendasikan kepada pihak puskesmas tersebut untuk meningkatkan pemberian informasi tentang pelayanan antenatal kepada ibu hamil dan keluarganya.
\end{abstract}

Kata kunci: tenaga kesehatan; antenatal care, pengetahuan; jarak rumah

\section{PENDAHULUAN}

Menurut World Health Organization (WHO) antenatal care (ANC) adalah pengawasan sebelum persalinan terutama ditujukan pada pertumbuhan dan perkembangan janin dalam rahim. Pemeriksaan antenatal care (ANC) bagi ibu hamil ber- tujuan untuk mendeteksi kelainankelainan yang mungkin ada atau akan timbul pada kehamilan tersebut. Cakupan pelayanan antenatal dapat dipantau melalui cakupan pelayanan K1 dan K4. Ibu hamil dianjurkan untuk melakukan pengawasan antenatal setidaknya 
sebanyak 4 kali (Usman et al., 2018).

Salah satu indikator keberhasilan pembangunan dalam sektor kesehatan adalah tingkat angka kematian ibu dan anak, hal ini menggambarkan bagaimana kualitas kesehatan ibu. Angka kematian ibu (AKI) di Indonesia masih relatif lebih tinggi jika dibandingkan dengan negara-negara anggota ASEAN. Risiko kematian ibu karena melahirkan di Indonesia adalah 1 dari 65, dibandingkan dengan 1 dari 1.100 di Thailand (Kementerian Kesehatan RI, 2016).

Berdasarkan Profil Kesehatan Indonesia 2016, Penurunan AKI di Indonesia terjadi sejak tahun 1991 sampai dengan 2007, yaitu dari 390 menjadi 228. Namun, SDKI tahun 2012 menunjukkan peningkatan AKI yang signifikan yaitu menjadi 359 kematian ibu per 100.000 kelahiran hidup. Pada tahun 2015 AKI kembali mengalami penurunan menjadi 305 kematian ibu per 100.000 kelahiran hidup berdasarkan hasil Survei Penduduk Antar Sensus 2015 .

Data diperoleh dari Dinas Kesehatan Provinsi Sulawesi Selatan menunjukkan bahwa cakupan pelayanan KI tahun 2017 dimana kabupaten paling tinggi cakupannya yaitu Kabupaten Enrekang sebesar 105,30\% dan terendah di Kabupaten Selayar sebesar 93,76\% dan untuk cakupan pelayanan K4 dimana kabupaten paling tinggi cakupannya yaitu Kabupaten Takalar sebesar 98,49\% dan terendah Kabupaten Sidrap sebesar 78,01\% (Kementerian Kesehatan RI, 2017).

Berdasarkan data Dinas Kesehatan Kabupaten Wajo untuk tingkat kabupaten dimana cakupan K1 pada tahun 2015 sebesar 101,0\% sedangkan untuk cakupan K4 sebesar 96,5\%, cakupan K1 pada tahun 2016 dan 2017 sebesar 97,8\% dan 98,8\% sedangkan untuk cakupan $\mathrm{K} 4$ pada tahun 2016 dan 2017 sebesar 94,0\% dan 93,1\%. Secara nasional masih berada di bawah target standar pelayanan minimal (SPM) yaitu sebesar 95\%. Jika dibandingkan dengan target yang ingin di capai dalam pelaksanaan pembangunan kesehatan maka data untuk cakupan K1 dan K4 belum mencapai target di Puskesmas Penrang, dimana jumlah cakupan K1 dari tahun 2015-2017 masingmasing sebesar $90,0 \%, 74,9 \%$ dan $91,8 \%$ sementara untuk cakupan K4 dari tahun 2015-2017 masing-masing sebesar 90,9\%, $74,6 \%$ dan 82,5\%. (Dinas Kesehatan Provinsi Sulawesi Selatan, 2019)

Pemanfaatan pelayanan antenatal care oleh ibu hamil belum sepenuhnya sesuai dengan pedoman yang ditetapkan. Hal ini cenderung menyulitkan tenaga kesehatan dalam melakukan pembinaan pemeliharaan kesehatan ibu hamil secara teratur dan menyeluruh, termasuk deteksi dini terhadap faktor resiko kehamilan yang penting untuk segera ditangani.5 Kurangnya pemanfaatan antenatal care oleh ibu hamil berhubungan 
dengan banyak fakor. salah satu diantara adalah penelitian di Etiopia ditemukan bahwa usia, pendidikan ibu, pengetahuan dan juga dukungan keluarga merupakan faktorfaktor yang mempengaruhi kunjungan ibu hamil (Notoatmodjo, 2007).

Berdasarkan maslah yang telah dipaparkan mengenai kepatuhan antenatal care maka peneliti tertarik untuk meneliti faktor-faktor yang mempengaruhi kunjungan antenatal care (ANC) ibu hamil di wilayah kerja Puskesmas Penrang Kecamatan Penrang Kab. Wajo.

\section{METODE PENELITIAN}

Jenis Penelitian yang digunakan adalah penelitian kuantitatif menggunakan pendekatan deskriptif analitik dengan metode cross sectional yang bertujuan untuk mengetahui tentang faktor yang mempengaruhi kunjungan Antenatal Care (ANC) ibu hamil diwilayah kerja Puskesmas Penrang Kecamatan Penrang Kabupaten Wajo. Sampel dalam penelitian ini diambil dengan menggunakan teknik Purposive Sampling sebanyak 69 sampel.

Analisis data dilakukan secara deskriptif yang menjelaskan gambaran faktor-faktor yang mempengaruhi kunjungan antenatal care (ANC) ibu hamil di wilayah kerja Puskesmas Penrang Kecamatan Penrang Kabupaten Wajo dengan cara mendeskripsikan tiap-tiap variabel yang digunakan dalam penelitian yaitu distribusi frekuensi dalam bentuk tabel.

\section{HASIL PENELITIAN}

Berdasarkan tabel 1, menunjukkan bahwa distribusi frekuensi karakteristik responden dan variabel-variabel penelitian dengan total 69 responden, umur responden di wilayah kerja Puskesmas Penrang terkait pelayanan ANC yang beresiko tinggi yaitu umur $<20$ dan $>3515.9 \%$, dan yang beresiko rendah yaitu umur 20-35 84.1\%. Pekerjaan responden dominan berstatus pekerja sebagai IRT sebanyak $50(72.5 \%)$ dan status pekerjaan sebagai PNS 1 (1.4\%). Tingkat pendidikan responden yang paling rendah yaitu tidak tamat SD sebanyak 5 $(7.2 \%)$ dan yang terbanyak yaitu tamat SD sebanyak $23(33.3 \%)$.

Berdasarkan tabel 2, menunjukkan bahwa persentase berdasarkan kunjungan ANC ibu hamil sebanyak $50 \quad(72.5 \%)$ lengkap dan 19 (27.5\%) memiliki kunjungan ANC tidak lengkap. persentase berdasarkan pengetahuan ibu sebanyak 38 (55.1\%) cukup dan 31 (44.9\%) memiliki pengetahuan kurang. persentase berdasarkan jarak rumah yang tergolong dekat sebanyak 49 (71.0\%) dan jarak yang tergolong jauh sebanyak 20 (29.0\%). persentase berdasarkan status ekonomi cukup sebanyak $41(59.4 \%)$ dan 28 (40.6\%) berstatus ekonomi kurang. suami/keluarga 
memberikan dukungan cukup sebanyak 48 $(69.6 \%)$ dan suami kurang memberikan dukungan sebanyak 21 (30.4\%). petugas kesehatan memberikan dukungan cukup sebanyak 49 (71.0\%), dan petugas kesehatan kurang memberikan dukungan sebanyak $26(29.0 \%)$.

Berdasarkan tabel 3, menunjukkan bahwa Crosstabulasi Variabel penelitian terhadap total 69 responden menunjukkan dangkan jarak rumah tidak berhubungan dengan kunjungan ANC.

\section{PEMBAHASAN}

Faktor-faktor yang mempengaruhi pengetahuan adalah pendidikan, paritas, usia dan pekerjaan. Makin tinggi tingkat pendidikan seseorang, maka makin mudah menerima informasi sehingga makin banyak pula pengetahuan tentang pemeriksaan

Tabel 1. Distribusi Karakteristik Responden yang Memeriksakan Kehamilan di Puskesmas

\begin{tabular}{lcc}
\hline \multicolumn{1}{c}{ Karakteristik Responden } & Total & n \\
\cline { 2 - 3 } & & \\
\hline Umur & 58 & 84.1 \\
Risiko rendah (20-35 tahun) & 11 & 15.9 \\
Risiko tinggi (<20 dan $>35$ tahun) & 69 & 100 \\
Total & & 72.5 \\
Pekerjaan & 50 & 1.4 \\
IRT & 1 & 15.9 \\
PNS & 11 & 10.1 \\
Pegawai Swasta & 7 & 100 \\
Wiraswasta & 69 & 7.2 \\
Total & & 33.3 \\
Pendidikan & 5 & 17.4 \\
Tidak sekolah & 23 & 27.5 \\
SD & 12 & 14.5 \\
SLTP & 19 & 100 \\
SLTA & 10 & \\
Perguruan tinggi & 69 & \\
Total & & \\
\hline
\end{tabular}

Sumber: Data Primer, 2018

bahwa variabel pengetahuan $(\mathrm{p}=0.000)$, jarak rumah $(\mathrm{p}=0.237)$, status sosial ekonomi $(\mathrm{p}=0.001), \quad$ dukungan suami/keluarga $(\mathrm{p}=0.001)$, dukungan petugas kesehatan $(\mathrm{p}=0.000)$. Dari 5 variabel yang diteliti terdapat 4 variabel yang berhubungan dengan kunjungan ANC yaitu pengetahuan, status sosial ekonomi, dukungan suami/keluarga, dan dukungan petugas kesehatan. Se- kesehatan yang diterima, Sebaliknya pendidikan yang kurang akan menghambat perkembangan sikap seseorang terhadap nilai-nilai baru yang diperkenalkan. Usia mempengaruhi terhadap daya tangkap dan pola pikir seseorang dalam menerima informasi. Dengan pekerjaan responden sebagai ibu rumah tangga memberi peluang lebih besar kepada responden untuk lebih banyak 
mendapatkan informasi tentang pemeriksaan kehamilan sehingga pengetahuan responden semakin baik (Notoatmodjo, 2007).

Berdasarkan perhitungan analisis statistik chi-square diperoleh nilai $\mathrm{p}=$ 0.000 lebih kecil dari $=0.05$. Hasil cenderung adalah ibu yang memiliki pengetahuan yang baik mengenai pelayanan antenatal itu sendiri. Hasil penelitian ini sejalan dengan penelitian yang dilakukan oleh Rauf et al. (2013) yang menyatakan bahwa ada hubungan yang bermakna antara pengetahuan ibu dengan

Tabel 2. Analisis Univariat Kunjungan ANC Ibu Hamil di Puskesmas

\begin{tabular}{|c|c|c|}
\hline \multirow{2}{*}{ Variabel } & \multicolumn{2}{|c|}{ Total } \\
\hline & $\mathrm{n}$ & $\%$ \\
\hline \multicolumn{3}{|l|}{ Kunjungan ANC } \\
\hline Lengkap & 50 & 72.5 \\
\hline Tidak lengkap & 19 & 27.5 \\
\hline Total & 69 & 100 \\
\hline \multicolumn{3}{|l|}{ Pengetahuan } \\
\hline Cukup & 38 & 55.1 \\
\hline Kurang & 31 & 44.9 \\
\hline Total & 69 & 100 \\
\hline \multicolumn{3}{|l|}{ Jarak Rumah } \\
\hline Dekat & 49 & 71.0 \\
\hline Jauh & 20 & 29.0 \\
\hline Total & 69 & 100 \\
\hline \multicolumn{3}{|l|}{ Status Ekonomi } \\
\hline Cukup & 41 & 59.4 \\
\hline Kurang & 28 & 40.6 \\
\hline Total & 69 & 100 \\
\hline \multicolumn{3}{|l|}{ Dukungan Suami/keluarga } \\
\hline Cukup & 48 & 69.6 \\
\hline Kurang & 21 & 30.4 \\
\hline Total & 69 & 100 \\
\hline \multicolumn{3}{|l|}{ Dukungan Perugas Kesehatan } \\
\hline Cukup & 49 & 71.0 \\
\hline Kurang & 20 & 29.0 \\
\hline Total & 69 & 100 \\
\hline
\end{tabular}

Sumber: Data Primer, 2018

penelitian memperlihatkan bahwa terdapat hubungan antara pengetahuan ibu dengan kunjungan ANC karena pengetahuan yang cukup memegang peranan penting terhadap kunjungan ANC. Terdapat kecenderungan tingkat pengetahuan dengan pemanfaatan pelayanan antenatal care, dimana ibu yang mendapatkan pelayanan antenatal care kunjungan ANC.

Dengan keteraturan kunjungan ANC tersebut maka perkembangan kehamilan dan kondisi janin ibu dapat dipantau terusmenerus, sehingga apabila ditemukan adanya kelainan ataupun komplikasi dalam kehamilan bisa segera ditangani. Dengan begitu kualitas kesehatan ibu dan anak akan 
semakin meningkat dan angka kematian ibu dan bayi bisa ditekan seminimal mungkin.

Berdasarkan hasil penelitian menunjukkan bahwa Ibu hamil dengan pengetahuan kurang namun tetap melakukan kunjungan ANC lengkap disebabkan oleh faktor motivasi dan faktor lingkungan, kunjungan ANC disebabkan oleh faktor sikap ibu. Dimana ibu menganggap kehamilannya masih muda dan tidak ada komplikasi, sehingga ibu tidak perlu untuk melakukan kunjungan ANC.

Keterjangkauan atau akses artinya layanan kesehatan itu harus dapat di-

Tabel 3. Analisis Bivariat Kunjungan ANC Ibu Hamil di Puskesmas

\begin{tabular}{|c|c|c|c|c|c|c|c|}
\hline \multirow{3}{*}{ Variabel } & \multicolumn{4}{|c|}{ Kunjungan ANC } & \multicolumn{2}{|c|}{ Jumlah } & \multirow{3}{*}{$p$} \\
\hline & \multicolumn{2}{|c|}{ Lengkap } & \multicolumn{2}{|c|}{ Tidak Lengkap } & \multirow{2}{*}{$\mathrm{N}$} & \multirow{2}{*}{$\%$} & \\
\hline & $\mathrm{n}$ & $\%$ & $\mathrm{n}$ & $\%$ & & & \\
\hline \multicolumn{8}{|l|}{ Pengetahuan } \\
\hline Cukup & 37 & 53.6 & 1 & 1.4 & 38 & 55.1 & \multirow{3}{*}{0.000} \\
\hline Kurang & 13 & 18.8 & 18 & 26.1 & 31 & 44.9 & \\
\hline Total & 50 & 72.5 & 19 & 27.5 & 69 & 100 & \\
\hline \multicolumn{8}{|l|}{ Jarak Rumah } \\
\hline Dekat & 38 & 55.1 & 11 & 15.9 & 49 & 71.0 & \multirow{3}{*}{0.237} \\
\hline Jauh & 12 & 17.4 & 8 & 11.6 & 20 & 29.0 & \\
\hline Total & 50 & 72.5 & 19 & 27.5 & 69 & 100 & \\
\hline \multicolumn{8}{|l|}{ Status Ekonomi } \\
\hline Cukup & 36 & 52.2 & 5 & 7.2 & 41 & 59.4 & \multirow{3}{*}{0.001} \\
\hline Kurang & 14 & 20.3 & 14 & 20.3 & 28 & 40.6 & \\
\hline Total & 50 & 72.5 & 19 & 27.5 & 69 & 100 & \\
\hline \multicolumn{8}{|c|}{ Dukungan Suami/keluarga } \\
\hline Cukup & 43 & 62.3 & 5 & 7.2 & 48 & 69.6 & \multirow{3}{*}{0.000} \\
\hline Kurang & 7 & 10.1 & 14 & 20.3 & 21 & 30.4 & \\
\hline Total & 50 & 72.5 & 19 & 27.5 & 69 & 100 & \\
\hline \multicolumn{8}{|l|}{ Dukungan Petugas } \\
\hline \multicolumn{8}{|l|}{ Kesehatan } \\
\hline Cukup & 43 & 62.3 & 6 & 8.7 & 49 & 71.0 & \multirow[t]{3}{*}{0.000} \\
\hline Kurang & 7 & 10.1 & 13 & 18.8 & 20 & 29.0 & \\
\hline Total & 50 & 72.5 & 19 & 27.5 & 69 & 100 & \\
\hline
\end{tabular}

Sumber: Data Primer, 2017

yaitu dukungan suami/keluarga dimana 13 orang ibu hamil $(18,8 \%)$ dari 69 orang ibu hamil yang berpengetahuan kurang mendapatkan dukungan suami yang cukup sebanyak 43(62,3\%) dan hanya 7 orang diantaranya yang kurang mendapatkan dukungan dari suami maupun keluarga dari 69 ibu hamil. Sedangkan ibu hamil dengan pengetahuan baik tetapi tidak melakukan capai oleh masyarakat, tidak terhalang oleh keadaan geografis, sosial, ekonomi, organisasi dan bahasa. Ketersediaan dan keterjangkauan sumber daya kesehatan merupakan salah satu faktor yang memberikan kontribusi terhadap perilaku sehat. Keterjangkauan atau akses dengan mutu tidak memiliki hubungan disebabkan karena pasien merasa bermutu tidaknya pusk- 
esmas, pasien tetap memanfaatkan pelayanan kesehatan di puskesmas itu sebab jarak dari rumah ke pelayanan kesehatan mudah di jangkau atau di akses (Pohan, 2013).

Berdasarkan perhitungan analisis statistik chi-square diperoleh nilai $\mathrm{p}=0.237$ lebih besar dari nilai $=0.05$. Hasil penelitian ini menjelaskan bahwa tidak terdapat hubungan yang signifikan antara jarak rumah responden ketempat pelayanan kesehatan dengan kunjungan ANC. Kondisi membuktikan bahwa jarak dan waktu tempuh bukan menjadi prediktor terhadap aksebilitas pada pelayanan kesehatan, artinya baik ibu yang memiliki persepsi jarak tempuh jauh maupun dekat untuk menjangkau tempat pelayanan memiliki peluang yang sama untuk berstatus pemeriksaan kehamilannya tidak lengkap. Hasil ini sejalan dengan penelitian Nurihwani (2017) yang menyatakan bahwa tidak ada hubungan yang bermakna antara jarak tempat tinggal ketempat pelayanan kesehatan dengan kunjungan K4

Berdasarkan hasil penelitian menunjukkan bahwa beberapa rumah yang jaraknya jauh dari sarana dan fasilitas kesehatan akan tetapi dari segi transportasi sudah memadai untuk menjangkau tempat pelayanan kesehatan, karena umumnya masyarakat memiliki kendaraan roda dua dimana jika dilihat dari distribusi responden berdasar- kan status ekonomi umumnya status ekonomi cukup yaitu sebanyak 41(59,4\%) dari 69 responden. Hal lain yang ditemukan dalam penelitian ini adalah ada beberapa rumah yang jarak rumahnya dekat dengan sarana dan fasilitas kesehatan akan tetapi responden jarang memeriksakan kesehatannya karena mereka hanya akan pergi ke tempat pelayanan kesehatan apabila mendapat keluhan.

Sosial ekonomi merupakan gambaran tingkat kehidupan seseorang dalam masyarakat yang ditentukan dengan variabel pendapatan, pendidikan dan pekerjaan, karena ini dapat mempengaruhi aspek kehidupan termasuk pemeliharaan kesehatan. Keadaan sosial ekonomi yang rendah pada umumnya berkaitan erat dengan berbagai masalah kesehatan yang dihadapi. (Rauf et al., 2013)

Berdasarkan perhitungan analisis statistik chi-square diperoleh nilai $\mathrm{p}=$ 0.001 lebih kecil dari nilai $=0.05$. Hasil penelitian menunjukkan bahwa ada hubungan antara status sosial ekonomi dengan kunjungan ANC. Pendapatan mempengaruhi kunjungan $\mathrm{ANC}$, hal ini disebabkan karena biaya penghidupan yang tinggi sehingga diperlukan pasien harus menyediakan dana yang diperlukan. Adapun tingkat ekonomi yang diteliti berdasarkan Upah Minimal Provinsi (UMP) adalah penghasilan sebesar Rp 
2.647.767,-- /bulan. Hal ini sesuai dengan penelitian yang dilakukan Lumempouw et al. (2016) bahwa terdapat hubungan yang signifikan antara pendapatan keluarga dengan kunjungan ANC.13

Status ekonomi sangat mempengaruhi kondisi psikologis ibu hamil. Ibu hamil dengan tingkat sosial ekonomi tinggi mempunyai kecemasan yang lebih rendah daripada ibu hamil yang berasal dari tingkat sosial ekonomi rendah. Hal ini berkaitan dengan biaya persalinan maupun biaya pemeliharaan bayi sampai dengan kehidupan dewasanya (Lumempouw et al., 2016).

Pendapatan keluarga rendah yang melakukan kunjungan ANC disebabkan oleh faktor adanya informasi dari teman atau tetangga bahwa pemeriksaan kehamilan di posyandu tidak dikenakan biaya atau gratis. Responden dengan pendapatan rendah tetapi tidak melakukan kunjungan ANC disebabkan oleh beberapa faktor diantara ibu hamil yang memeriksakan diri di PUSKESDES masih dipungut biaya pada saat pengambilan obat, serta responden juga mengaku yang memiliki paritas tinggi sudah merasa berpengalaman sehingga tidak perlu lagi memeriksakan kehamilannya. Sedangkan responden dengan pendapatan keluarga tinggi tetapi tidak melakukan kunjungan ANC disebabkan oleh faktor motivasi dan sikap yang dimiliki oleh re- sponden tersebut. (Susanto et al., 2016)

Dukungan suami merupakan sistem pendukung utama untuk memberikan perawatan langsung pada setiap keadaan sehat ataupun sakit. Peran suami/keluarga dalam pelayanan antenatal sangat penting, yaitu sebagai orang-orang yang paling dekat dengan responden yang harus memotivasi responden untuk memeriksakan kehamilannya serta mendukung responden baik secara moril maupun materil sehingga responden dapat melalui kehamilannya dengan baik.12

Berdasarkan perhitungan analisis statistik chi-square diperoleh nilai $p=0.000$ lebih kecil dari nilai $=0.05$. hasil penelitian ini membuktikan terdapat hubungan yang signifikan antara dukungan suami/keluarga terhadap kunjungan ANC. Hasil penelitian ini sejalan dengan penelitian yang dilakukan Mardiah (2013) didapatkan bahwa terdapat hubungan yang signifikan antara dukungan suami dengan kunjungan ANC (Mardiyah et al., 2014).

Dukungan suami/keluarga sangat memegang peranan penting dalam perilaku ibu untuk melakukan pemeriksaan kehamilan. Hal tersebut oleh karena kekhawatiran dari keluarga terhadap masa kehamilan yang merupakan gerbang untuk menghadapi persalinan, semakin baik pemeriksaan kehamilannya maka pihak keluarga akan semakin tenang untuk menghadapi persalinan, kare- 
na dapat mengetahui kondisi kehamilannya serta kesehatan ibu dan bayinya (Fitrayeni et al., 2017).

Ibu hamil dengan suami tidak mendukung tetapi tetap melakukan kunjungan ANC disebabkan oleh faktor motivasi ibu itu sendiri. Ibu ingin menjaga janin yang dikandungnya hingga masa persalinan dalam kondisi ibu dan bayi sehat. Sedangkan ibu hamil yang suami mendukung tetapi tidak melakukan kunjungan ANC disebabkan oleh faktor paritas yang tinggi. dimana responden yang sudah mengalami kehamilan lebih dari dua kali sudah pasti mempunyai pengalaman lebih tentang pemeriksaan ANC daripada ibu yang pertama kali mengalami kehamilan. Semakin sering ibu memiliki riwayat melahirkan, kunjungan ANC menjadi berkurang karena ibu menganggap bahwa dia memiliki pengalaman yang cukup sehingga kurang termotivasi untuk memeriksakan kehamilannya (Dinas Kesehatan Provinsi Sulawesi Selatan, 2019).

Hubungan dukungan petugas kesehatan terhadap kunjungan ANC

Sikap petugas kesehatan akan membentuk persepsi ibu hamil tentang pelayanan antenatal. Petugas yang memberikan kesan yang baik terhadap ibu hamil serta menunjukkan kemampuan, ketelitian, keterampilan dalam mengatasi kesulitan yang dialami pasien dengan cepat sesuai dengan tuntunan akan membuat ibu hamil merasa percaya diri untuk memeriksakan kesehatan dan puas dengan pelayanan yang diberikan. Hal ini akan berdampak pada keinginan ibu untuk melanjutkan pemeriksaan kehamilan di pelayanan kesehatan tersebut (Mardiyah et al., 2014).

Berdasarkan perhitungan analisis statistik chi-square diperoleh nilai $\mathrm{p}=$ 0.000 lebih kecil dari nilai $=0.05$ berarti terdapat hubungan antara dukungan petugas kesehatan terhadap kunjungan ANC. Sebagian besar responden menilai dukungan petugas kesehatan dalam kategori cukup dan memenuhi kunjungan ANC. Sejalan dengan hasil penelitian Mardiah yang menyebutkan bahwa ada hubungan antara dukungan petugas kesehatan dengan kunjungan ANC. Semakin baik pelayanan yang di berikan oleh petugas, semakin tinggi tingkat pemanfaatan pelayanan ANC (Mardiyah et al., 2014)

Sikap petugas kesehatan yang ramah, memberikan pelayanan yang baik kepada responden sehingga meningkatkan kunjungan ANC ibu hamil. Sedangkan responden yang memiliki kunjungan ANC tidak lengkap karena mendapat pelayanan yang kurang baik dari petugas kesehatan. Hal ini disebabkan oleh karena terkadang petugas kesehatan sibuk sehingga lupa menjelaskan 
aspek-aspek pelayanan antenatal care dengan lengkap (Mardiyah et al., 2014).

\section{KESIMPULAN}

Berdasarkan hasil penelitian yang dilakukan di Puskesmas Penrang Kecamatan Penrang Kabupaten Wajo dapat disimpulkan sebagai berikut : Terdapat hubungan antara pengetahuan ibu, status sosial ekonomi, dukungan suami/keluarga dan dukungan petugas kesehatan dengan kunjungan antenatal care (ANC) Sedangkan jarak rumah tidak berhubungan dengan kunjungan ANC.

\section{SARAN}

Untuk meningkatkan dan mempertahankan pelayanan kesehatan diharapkan kerjasama semua pihak yakni Dinas Kesehatan memperhatikan sarana dan prasarana, Puskesmas meningkatkan pendekatan dan kerjasama dengan masyarakat, petugas kesehatan mengadakan penyuluhan kesehatan secara rutin minimal 2 kali seminggu tentang pemeriksaan antenatal care kepada ibu hamil, serta pelayanan yang didapatkan ketika pemeriksaan kehamilan di pelayanan kesehatan.

Diharapkan penelitian ini dapat bermanfaat bagi peneliti lainnya, dan peneliti selanjutnya melakukan penelitian serupa dengan desain yang berbeda yaitu kualitatif untuk mengkaji lebih dalam tentang faktor- faktor yang dapat mempengaruhi kunjungan antenatal Care (ANC).

\section{DAFTAR PUSTAKA}

Dinas Kesehatan Provinsi Sulawesi Selatan. (2019). Profil Kesehatan Provinsi Sulawesi Selatan Tahun 2018.

Fitrayeni, Suryati, \& Faranti, R. M. (2017).

Penyebab Rendahnya Kelengkapan

Kunjungan Antenatal Care Ibu Hamil

Di Wilayah Kerja Puskesmas

Pegambiran. Jurnal Kesehatan

Masyarakat Andalas, 10(1), 101.

https://doi.org/10.24893/jkma.10.1.101

$-107.2015$

Kementerian Kesehatan RI. (2016).

Pedoman Umum Program Indonesia

Sehat Dengan Pendekatan Keluarga.

Kementerian Kesehatan RI. (2017). Profil

Kesehatan Indonesia Tahun 2016.

Lumempouw, V. J. R., Kundre, R. M., \&

Bataha, Y. (2016). Hubungan Faktor

Sosial Ekonomi Ibu Hamil Dengan

Keteraturan Pemeriksaan Antental

Care (Anc) Di Puskesmas Ranotana

Weru Kecamatan Wanea Kota

Manado. Jurnal Keperawatan, 4(2), 17.

Mardiyah, U. L., Herawati, Y. T., \& Witcahyo, E. (2014). Faktor yang Berhubungan dengan Pemanfaatan Pelayanan Antenatal oleh Ibu Hamil di Wilayah Kerja Puskesmas Tempurejo Kabupaten Jember Tahun 2013. Pustaka Kesehatan, 2(1). https:// jurnal.unej.ac.id/index.php/JPK/article/ view/597

Notoatmodjo, S. (2007). Promosi kesehatan dan ilmu perilaku. In rineka cipta (Vol. 20). rineka cipta.

Nurihwani. (2017). Hubungan Dukungan Keluarga Terhadap Kepatuhan 
Pengobatan Antiretroviral (ARV) Pada Orang Dengan HIV dan AIDS (ODHA) di Puskesmas Jumpandang Baru. In UIN Alauddin. Universitas Islam Negeri Alauddin Makassar.

Pohan, I. S. (2013). Jaminan Mutu Layanan Kesehatan Dasar-Dasar Pengertian dan Penerapannya. EGC.

Rauf, N. I., Amir, M. Y., Akk, B., \& Masyarakat, F. K. (2013). Faktor yang Berhubungan dengan Pemanfaatan pelayanan Antenatal Care Di Puskesmas Minasa Upa Makassar Tahun 2013. Public Health, 1-11.
Susanto, J., Ahmad, L. A. I., \& Ismail, C. (2016). Faktor Yang Berhubungan Dengan Pemeriksaan Antenatal Care (Anc) Kunjungan 1 - Kunjungan 4 (K1 - K4) Pada Ibu Hamil Di RSUD Kota Kendari Tahun 2016. Jurnal Ilmiah Mahasiswa Kesehatan Masyarakat Unsyiah, 1(3), 1-7.

Usman, Suherman, N. U. D., \& Rusman, A. D. P. (2018). Faktor Yang Berhubungan Dengan Pemanfaatan Antenatal Care Di Puskesmas Madising Na Mario Kota Parepare. Jurnal Ilmiah Manusia Dan Kesehatan, 1(1), 1-15. 